\title{
The Value of Zoos for Science and Conservation
}

\author{
By Caroline Jarvis
}

For too long zoos have been regarded as places of entertainment where people go to laugh at the animals. But the modern zoo has important functions to fill and must take its place as a scientific and cultural institution beside the museum and the research station. The author, editor of the International Zoo Yearbook, suggests that zoos have three main functions: firstly, educational, where their opportunity is enormous - 150 million people a year go to see the half-million vertebrate animals in the $500 \mathrm{zoos}$ and aquaria listed in the Yearbook; secondly as repositories of data about wild animals; thirdly, as breeding centres for endangered species. She believes that a united organised breeding programme, using large units and with each zoo specialising in certain animals, could save many endangered species.

GVERYONE who is concerned with wild animals must be alarmed at the threat to their continued existence. Much has been said and written about the danger of extinction facing so much of the world's wildlife, and most of us are now familiar with the nature of the threat: the increase in human population and human technological demands on the natural environment, the cutting down of forests, draining of marshes, pollution of rivers, urbanisation of the sea-shore, over-harvesting of the sea, uncontrolled use of chemical pesticides, and everywhere a diminution of the wilderness areas of the world. The amount of undisturbed habitat remaining for wild animals and plants daily decreases. Some species are able to adapt sufficiently rapidly to the new environment created by man, but the majority are too specialised for a particular kind of habitat to be able to do this. Destroy the habitat and almost invariably you destroy the wild animals that live in it.

Where a direct conflict of interest occurs between man and wild animals or plants, the human interest takes precedence; immediate advantage usually has priority over long-term needs. But if wildlife is to survive to any extent, then we must persuade our governments, administrators, economists, property developers, business men and often even our scientists to adapt their plans to consider the interests of wild animals. If those who are most closely concerned with wild animals - the zoos, universities, research institutes, game departments -do not all fight for conservation, then the wild animals which are their work and their interest, the justification for their existence, will in many cases cease to exist. 
At the 1966 meeting of the British Association for the Advancement of Science, Professor Pringle, Linacre Professor of Zoology at Oxford University, made wild life conservation the theme of his presidential address.* In an important passage he said, "If the zoological community is convinced of the irreplaceable value of a stock of animals, any measure is justified to stop it being destroyed. If a burglar is breaking into your house, you are justified in stopping him 'by any reasonable means.' The community may disapprove. Mankind of the future will be grateful." And as regards the destruction of a species he went on, "No amount of immediate need can possibly counterbalance the advantage to mankind over the whole future of time which the preservation of a species will bring."

There are many arguments to justify this strong statement. There are the obvious commercial considerations - the folly of overexploiting our natural resources until we destroy them: the whalers slaughtering to extinction the animals on which their livelihood depends are a good example of this. There are the aesthetic and cultural reasons-the pleasure, recreation and education people derive from seeing wild animals, from having access to wilderness areas which are increasingly important and necessary to our urbanised civilisation. But more fundamental than any commercial or cultural consideration is the scientific justification for conservation.

In much research wild animals are the raw material of zoology and their continued existence for this reason is essential. We still have much to learn about our own evolution, behaviour, diseases and, above all, our own relation to the natural environment. Man has the power to control nature to a certain extent, but equally he is part of nature and in order to understand himself completely, he can only do so in the context of nature and wild animals. Two of the most serious problems facing the human race today are the control of human aggression and the control of human population expansion. As Konrad Lorenz has shown in his most recent book, On Aggression, there are clues to our own aggressive instincts and their possible control to be found in the study of animal aggression. Equally, the findings of animal behaviourists, in their studies of the effect of population densities on fertility and disease, may be related to human population problems. The continued existence of man may well depend on the continued existence of the natural environment and the wild animals and plants it contains. This is what conservation is about and this is why conservation is so important. It is urgent because unless much more is done to halt the uncontrolled destruction of wild animals and their environment it may well be too late.

In this situation, zoos have a very important part to play, though few of them seem to realise it. According to the most recent records

*Part of this address was reprinted in ORYX, December 1966, Vol. VIII, 6. 
of the International Zoo Yearbook there are now about half a million wild vertebrates living in about 500 zoos and aquaria. The significance of this huge figure is two-fold. It indicates the scale on which zoos are involved with wild animals and it means that zoos are more closely concerned with wild animals than is any other type of organisation. They have more immediate contact and are familiar with a wider range of creatures, they have more opportunity to record certain kinds of data and knowledge available to them than any university, research institute or game department. This is why zoos are potentially so important, both to conservation and to zoological research. Conservation depends on knowledge, zoological research depends on knowledge and it is knowledge that is at present locked up in such vast quantities in zoos. Nature has been described as a treasure house of knowledge and zoos are the caretakers of a considerable part of it. But only too often they are unaware of their responsibilities as caretakers, or even that they are caretakers at all.

\section{How Zoos Have Lagged Behind}

Zoos have an unfortunate record in conservation and research. It is true that one of the earliest known zoos, founded by the first emperor of the Chou dynasty in 1100 B.C., was known as an 'intelligence park' and was arranged as an educational and cultural display; it is true that the idea of a scientific zoo was formulated by the famous naturalist Buffon as early as the 18th century, and it is true that there are a number of well-established scientific zoos, such as London, New York, Philadelphia, Antwerp, West Berlin, and more recently, the San Diego, Washington and Frankfurt Zoos, and a nưmber of others. However, the concept of the zoo as a place of research and education, rather than a public spectacle and entertainment, is only just beginning to be established even in the scientific world, let alone in the minds of the general public. There has probably been less progress in zoo theory and practice during the past 4000 years than in any other comparable field. By the beginning of this century, many capital cities and indeed many smaller towns had well-established botanical gardens and museums, systematically arranged, administered by curators and associated with scientific research; aquaria have been accepted as scientific organisations since 1853 when the first public aquarium was opened by the Zoological Society of London. It is only zoos, with a few well-known exceptions, that have had no scientific standing. Whereas most botanical gardens, museums, and aquaria were automatically assumed to be places of learning and education, zoos were considered first and foremost to be places of amusement: you went to the zoo to laugh at the animals - but who ever heard of anyone going to laugh at a collection of plants, fishes or geological speoimens? I realise that in some ways this is a facile comparison but it emphasises that for many years the zoo, which should have been a 
place of research for the scientist and of wonder and education for the ordinary visitor, was thought to be little more than a circus. It is to me quite extraordinary that whereas collections of dead animals should be generally accepted as scientifically valuable, so few people have ever realised the huge scientific potential of a collection of living animals.

\section{The Chance for Education}

Now at last the climate of opinion is changing, and the very fact of this San Diego conference is a sign of change, and that zoos are beginning to be aware of their responsibilities. But it is not enough for them simply to associate themselves with conservation: they must take a positive lead, giving direction and assistance. They owe it to themselves and even more to the animals in their care to realise the potential of knowledge contained in a collection of living wild animals. Because zoos are in this unique position of close daily contact with the public and with wild animals, their influence on conservation and on zoology could be incalculable. Zoos are visited by upwards of 150 million people annually; if only one tenth can be made to leave the zoo emotionally and intellectually excited by the wild animals they have seen, then the benefit to conservation would be enormous. Zoos should teach the public what a wild animal is, why it is exciting, why it is interesting and why it is important that wild animals should not become extinct.

Apart from education, there are two other supremely valuable things that a zoo can do to help save the world's animals from extinction: the first is to record wild animal data, and the second is to breed endangered species in captivity. One of the main difficulties of wild animal conservation is the lack of knowledge about the basic requirements of the creatures we are trying to protect. It is astonishing how little is known about the biology and behaviour patterns of the majority of wild animal species, for relatively few studies in depth, such as Schaller's justly famous work on the mountain gorilla Gorilla g. beringei, have been made. Much of this necessary information, such as the animal's relationship to its environment, the ecology of its habitat, its natural diet, and many of its behaviour patterns admittedly can only be studied in the field, but at the same time there is a great mass of data impossible or extremely difficult for field workers to acquire which can most easily be obtained by studying the animals in captivity.

\section{A Vast Amount of Data}

Until very recently zoos seem to have been largely unaware of the immense amount of valuable information available to them, and of the importance of this information if it is accurately recorded. Only a few zoos have good record systems going back over many years, 
and even in these zoos the amount of information recorded is meagre and sometimes inaccurate. During the past few years there has been some improvement, as can be seen from the pages of the International Zoo Yearbook. In 1960, when the Yearbook was started by the Zoological Society of London, we listed about 300 zoos and aquaria; of these, about 170 returned our questionnaires, requesting information on breeding successes, research, rare animals, and a number of other subjects. In 1966 we circulated 588 zoos with the Yearbook questionnaires; 480 were returned, and of the 108 that did not reply (mostly the smaller Chinese, Soviet and South American zoos) 85 have never replied. Only 23 zoos that have returned the Yearbook questionnaires in the past failed to do so this year (1966). These figures mean that approximately 500 zoos all over the world are regularly recording information for the Yearbook on their breeding successes, their rare animals and their research, and this in itself is making a valuable contribution to zoological knowledge. Moreover, the standard and quality of the contributions submitted have also improved. In 1960 the small municipal zoos, if they replied at all, would only send us the sketchiest of answers stating, for example in the breeding section, that they had bred "a few deer and ducks" during the previous year. Today, the breeding lists are often set out in great detail with animals listed under their scientific names. Another encouraging development is that while in 1960 it was only the major scientific zoos that sent us papers and reports on the care, breeding and nutrition of their animals, today we receive reports containing much valuable information, often never recorded before, from some of the smallest zoos.

The interest in data provided by zoos extends beyond the zoo profession. Through the Yearbook and through the efforts of the zoos that contribute to it, zoologists and conservationists are beginning to be aware of the increasing amount of zoological data being made available to zoos. The sales of the Yearbook are evidence of this new interest: it is bought not only by zoos but by zoologists in universities and scientific research institutes from Ulan Bator in Outer Mongolia, to Novosibirsk in Siberia, Anchorage in Alaska and Mount Hagen in Western New Guinea.

\section{Difficult in the Wild, Easy in the Zoo}

The amount of information waiting to be recorded in zoos is limitless. Certain basic data on reproduction, and in particular on the duration and periodicity of oestrus, on gestation and incubation periods, development and changes in dentition in the young, physiological and behavioural changes during growth to maturity, animal disease and certain aspects of animal behaviour are undoubtedly more easily studied in zoos. The difficulties of recording accurate data on gestation periods in a wild troop of monkeys, for example, are obvious, as are those of recording accurate data on the behavioural and physiological development of neonate young. Equally, zoos can record information 
on animals about which, because of the remoteness of their habitat, very little is known; a good example of this is the giant panda Ailuropoda melanoleuca, which lives in the high, dense bamboo forests of the Szechuan mountains, and possibly Yunnan and Tibet. The terrain is precipitous, often remote from civilisation, the bamboo forests almost impenetrable, and the panda solitary except during the breeding season. It ranges over a wide territory, moving through small tunnels in the bamboo. For all these reasons it has been difficult even for Chinese zoologists to find the giant panda in the wild, let alone record any certain, accurate information on its breeding biology and behavour. It was only when the Peking Zoo succeeded in breoding the giant panda that Chinese zoologists were able to record for the first time data on mating behaviour, oestrus, gestation period, behaviour of the mother with the young, and development and growth of the young panda.

Another valuable use of information recorded by zoos is the possibility of doing comparative studies, surveying incidence of breeding seasons of a particular species throughout the world, collecting data on a particular disease or group of diseases or studying the nutrition of animals in captivity. Already at the London Zoo extensive work on comparative medicine and comparative physiology is being done at the Nuffield and Wellcome Institutes, while at San Diego an important Animal Virus Centre has recently been established, and there are many other examples.

\section{Essential Facts for Conservation}

The recording of information on wild animals in captivity is not only useful to the zoos themselves, helping them to maintain and breed their animals more efficiently, but it is of considerable scientific value to research workers in many different fields: comparative medicine, comparative behaviour, and of course to conservation. If wild animals are to continue to exist at all, it will have to be in game parks, reserves and areas where territory may well be limited by man rather than by their physical and behavioural needs. In order to main. tain animals in these conditions of semi-captivity, we shall have to find out a great deal more about their behaviour and biology-and this is where zoos wth their fund of wild animal data can provide invaluable help.

However, despite these improvements, in the case of the majority of zoos the effect is minimal. If information recorded by zoos is to be valuable it must be much more extensive, much more methodical, much less haphazard than it is at present, and two things are essential: a good records system and efficient techniques for animal identification. The records need not be complicated but they must be accurate and precise. All zoos should record a basic minimum of data on their wild animals, preferably on a card index system, listing every individual identifiable animal in the collection, the date of its arrival, 
its estimated age and weight on arrival, the locality where it was obtained, its identifying marks, its sex, the dates when it mated or gave birth to young, notes on any illnesses during its lifetime, the date of death or departure and the cause of death or departure. In order to try and standardise the recording of information the International Zoo Yearbook is preparing a series of publications entitled "Guides to the Study of Wild Animals in Captivity," indicating what types of behavour and information should be recorded.

\section{The Wild Animal Bank}

This brings me to the final part of my talk: the role of the zoo as a wild animal bank, as a reserve where species that are endangered in their natural habitat can be bred in captivity over generations in order to preserve the species. Once again I should like to quote from Professor Pringle's address to the British Association meeting: "If the march of material progress makes it inevitable that whole environments will be destroyed and all animals and plants that live in them, one thing we can do is to urge the necessity for living museums, for artificially maintained nucleus stocks of the material which would otherwise be lost. This means a new and expanded role for zoological gardens. I suggest that the benefit and value to mankind in the future would be as great as that conferred by all the art museums of the world together." One very significant thing about this statement is that it is made by someone outside the zoo world, by a university professor. Zoos during the past few years have become increasingly aware of the role they could play in breeding endangered species, and indeed this has been the subject of several Yearbook forewords, but it is a sign of the times that this should be recognised at a gathering of world scientists.

We know that it is possible to preserve certain wild species in captivity over many generations, given a large enough gene pool, adequate nutrition, and careful culling of inferior specimens. The Mongolian wild horse Equus przewalskii, Père David's deer Elaphurus davidianus, European bison Bison bonasus, and Hawaiian goose Branta sandvicensis, are all well-known examples of species that have become extinct or nearly extinct in the wild, but which have been preserved in captivity. Another less well-known example is that of the eland antelope Tauritagus ory $x$ at Askaniya Nova Zoopark in the Ukraine. Admittedly this is not a rare animal, but it is an excellent example of a species that has been maintained in captivity over many years, with no introduction of fresh blood, and yet remains to all intents and purposes the same as the wild eland in Africa. Eight eland were brought to Askaniya Nova in 1892 when the zoopark was founded. Between 1897, when the animals started breeding, and 1964, 408 young were born. At first three or four young were born each year, and there were periods during the revolution and the first and second world wars, when the breeding rate declined, but the elands survived and today are breeding at the rate of 14 to 16 a year. The 
herd now numbers 42 animals. At the same time much interesting research on the physiology of the eland and the biochemistry of eland milk has been undertaken. The findings of zoologists at Askaniya Nova are extremely important and will complement attempts that are being made in Africa to breed this species as a game crop to be culled regularly for meat. It is a good example, demonstrating how valuable research undertaken in zoos can be to scientists in other fields.

\section{Breeding of Rare Species}

Now this could obviously be done with a number of other mammal and bird species. As a result of improved animal husbandry and the zoos' greater awareness of the importance of breeding, breeding successes are increasing annually. In 1965 a total of 1404 species and subspecies of mammals, birds, reptiles and amphibians were recorded in volume 7 of the Yearbook as having been bred in zoos. Of these, 75 forms are listed by the IUCN as being rare or endangered in the wild; and when this figure is compared with the total of 158 rare forms exhibited by zoos in 1965, the percentage of rare species being bred is an encouraging one. However, we do not know how many of these breeding successes are second generation captive breeding; I suspect that there are very few.

At the moment it is true to say that in the majority of zoos rare animals breed despite the zoos rather than because of them. It has been said with some exaggeration, that one of the puzzling things about wild animals in captivity is why they do breed rather than why they don't. In the past animals have been kept in zoos primarily for exhibition rather than for breeding, and only too often the demands of these functions conflict. The need to show the animals to the public, the appeal of the baby animal, the lack of accommodation for separating females during and immediately after birth, or for isolating the male outside the mating season, the refusal to cull inferior or aged specimens, the sale of young zoo-bred stock, all mean that a zoo is seldom able to breed up a large group of one species. Too often a 'breeding group' consists of a male and one or two females. The breeding male is seldom replaced before he dies, so that when he does die no suitable replacement male is available, and the breeding group is broken up. Moreover, numbers are usually so small that the stock is often wiped out overnight by accident or disease.

\section{Not Just for Show}

If zoos are to become real wild animal banks, then the whole attitude to breeding rare species will have to change. Breeding should not be treated casually, as a public show, as a source of extra money, or as occupational therapy for the animals, but as an end in itself. And zoos should pay as much attention to the breeding of their animals as a racehorse owner would to the running of his stud. Where breeding has been made one of the main aims of a zoo, as at Basel Zoo or the Catskill Game Farm, then the results have been startlingly good. 
Animals, particularly herd animals, should be kept in large enough groups to ensure that some sort of selection of old or inferior specimens can be undertaken. Herds should be scattered in several places, and almost certainly breeding centres should be administered separately from the zoo. The animals in the breeding centres can certainly be exhibited to the public, and it is obviously important that they should be, because it is by seeing these creatures that visitors will become interested in their conservation. But with rare species, exhibition must take second place to breeding. At the same time zoos, especially smaller zoos, should concentrate on breeding a few species rather than a large range of animals. Breeding must also be accompanied by accurate and detailed records and by proper identification of the animals concerned. In many cases it will be essential for studbooks to be started along the lines of those for the Przewalski horse, the European bison, and more recently, the admirable studbooks for the addax Addax nasomaculatus, scimitarhorned oryx Oryx tao and anoa Anoa depressicornis, maintained at San Diego Zoo. If we plan to breed species in captivity over many generations, either for conservation or zoo purposes, then accurate records of breeding lines, mortality rates, and the degree of inbreeding occurring must be kept.

\section{Co-operation in Research}

Basically, intensive breeding of rare species should, wherever possible, be accompanied by a research programme into the nutrition, behaviour, breeding biology and life history of that species. Nutritional research is particularly important because, despite the pioneer work undertaken by the Penrose Research Laboratory at Philadelphia Zoo, and at Basel Zoo, the diets of many zoos animals are both nutricionally and ethologically inadequate. If zoos do not have the funds to undertake this kind of research themselves, then they should make their resources available to outside research workers.

On a wider level, if zoos are to fulfil their role in science and conservation, there should be more co-operation between zoos and universities, game departments and conservation associations. Zoos should be able to undertake research projects for game departments, and equally research departments, should co-operate with zoos. Meetings, such as the zoos and conservation conference held at the Zoological Society of London in 1964 and this San Diego conference, should be held more often, and ideally I should like to see the formation of an international federation of all organisations concerned with the care, breoding and study of wild animals - zoos, universities, research institutes, game departments and conservation organisations-with regular meetings to exchange information. A further development of this would be to have an international centre for collecting basic data on wild animals in captivity, and for all zoos to use the same methods and card systems for recording these basic data. 
To sum up: the whole concept of the nature and function of the zoo is changing and it has to change. The zoo must take its place alongside the museum, the university and the research institute as one of society's most important cultural and scientific assets. It must become a centre of education, learning and research, both in its own interests, and in the interests of animals and mankind as a whole. Zoos are the trustees of wild animals in their care and as trustees they have great responsibilities. They are so closely concerned with wild animals that they are in a position of unique opportunity and power. By education and publicity, by making available their funds of wild animal data, by research, by breeding projects, by mutual co-operation, zoos have the power to ensure that the wild animals of the world do not become extinct. And if they can achieve this, they will have achieved something of inestimable value and importance to the survival of the human species. But this can only be done if zoos are prepared to spend very considerable time, thought, effort and expense. It is too late, the problem too urgent, the consequences of its neglect too serious, merely to pay lip service to conservation, as does the majority of mankind. Zoos cannot afford to ignore conservation of wild animals; even more important $I$ honestly believe that they can save them. 